\title{
Pemanfaatan Sosial Media Sebagai Wujud Inovasi Dalam Pelayanan Publik Oleh Ombudsman Ri Bengkulu
}

\author{
Fitria Yuliani ${ }^{1}$, Rekho Adriadi ${ }^{2}$, Linda Safitra ${ }^{3}$

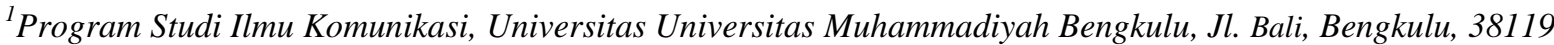 \\ E-mail: fitria@umb.ac.id \\ ${ }^{2}$ Program Studi Administrasi Negara, Universitas Universitas Muhammadiyah Bengkulu, Jl. Bali, Bengkulu, 38119 \\ E-mail: fitria@umb.ac.id \\ ${ }^{3}$ Program Studi Sosiologi, Universitas Universitas Muhammadiyah Bengkulu, Jl. Bali, Bengkulu, 38119 \\ E-mail: fitria@umb.ac.id
}

\begin{abstract}
The use of social media today is not only functioned for personal interests, but also for the benefit of groups, organizations, and state institutions in terms of public services as conducted by the Ombudsman RI Bengkulu who utilize social media as a medium of public service in Bengkulu province. It is interesting to study about the new "concept" that is applied in the process of public service, especially one of the challenges that faced by these institutions is the lack of public understanding of the existence of these institutions, so that innovation is basically needed in reaching out to the community and carrying out the role as a state institution with totality in carrying out public services as an objective of the existence of this state institution. This research was conducted to see how the social media was utilized by Ombudsman RI Bengkulu in conducting public services as a form of innovation in public service by Ombudsman RI Bengkulu. The research method was using a qualitative descriptive approach where the research results were analyzed by using the theory of diffusion of innovations. The research subjects in this case are the Ombudsman RI Bengkulu, and the social media users who have accessed the Ombudsman RI Bengkulu social media page, which is proven by digital traces left in the form of likes and comments on the Ombudsman RI Bengkulu Social media. The four elements in the innovation diffusion process show the innovations that applied in the public service process by the Ombudsman RI Bengkulu and how the utilization of these innovations in the public service process by the Ombudsman RI Bengkulu. Innovation in this regard is related to the use of social media as a medium for socialization and raising complaints in the process of public service by the Ombudsman RI Bengkulu. It is said as a form of innovation because the process of public services that is usually done traditionally both directly and through traditional media so that it costs quite a lot, with the use of social media can be done more easily, quickly and efficiently.
\end{abstract}

Keywords - Innovation; Service; Public; Social Media; Ombudsman RI Gender Bengkulu.

\section{LATAR BELAKANG}

Dapat dikatakan sosial media dewasa ini dimanfaatkan dalam banyak bidang kehidupan manusia, baik dalam bidang sosial, ekonomi, politik maupun budaya. Dimanfaatkan oleh tidak hanya individu, tapi juga oleh kelompok, organisasi maupun lembaga negara. Hal ini menunjukkan adanya pergeseran fungsi penggunaan sosial media. Dikatakan demikian karena di awal kemunculannya, sosial media lebih difungsikan sebagai media eksistensi diri, dimana penggunaanya memanfaatkan sosial media dalam menjelaskan identitas diri mereka melalui postingan di sosial media, berbagai tentang keseharian dan aktivitas mereka, saling berbagi dan berinteraksi satu sama lain maupun membentuk kelompok sesuai dengan interest dan kepentingan masing-masing pengguna. Hal ini pun sesuai dengan fungsi dari sosial media itu sendiri menurut Taprial\&Kanwar yakni identity, conversations, sharing, presence, relationship, reputation, dan groups (2012:31).

Namun seiring dengan perkembangan teknologi informasi dan komunikasi dimana masyarakat sekarang banyak bergantung pada pemanfaatan internet, termasuk sosial media sebagai platform yang paling banyak diakses oleh pengguna internet sebagaimana yang dikemukakan oleh situs Global Digital Report Hootsuite yang mendata tingkat penggunaan sosial media di Indonesia pada tahun 2019 yakni sejumlah 150 juta total pengguna dan menjadi mayoritas dari penggunaan internet oleh para user (wearesocial.com/global-digital-report-2019). Penggunaan sosial media tersebut tidak hanya difungsikan untuk kepentingan pribadi, namun juga untuk kepentingan kelompok, organisasi, maupun lembaga negara dalam hal pelayanan publik sebagaimana yang dilakukan oleh Ombudsman RI Bengkulu yang memanfaatkan sosial media sebagai medium pelayanan publik di provinsi Bengkulu.

Dikatakan sebagai wujud dari inovasi dalam pelayanan publik pada dasarnya dikarenakan pergeseran fungsi dan pemanfaatan sosial media yang dalam hal ini tidak hanya digunakan oleh individu, namun juga oleh Lembaga Negara tidak hanya untuk kepentingan pribadi namun juga untuk kepentingan lembaga dan masyarakat yang mana dalam tujuannya untuk kepentingan pelayanan publik. Ombudsman itu sendiri merupakan lembaga negara yang memiliki kewenangan dalam mengawasi penyelenggaraan pelayanan publik baik yang diselenggarakan oleh penyelenggara negara dan pemerintahan (UU No.37/2008 
pasal 1 tentang Ombudsman RI). Pun Ombudsman RI melakukan pelayanan publik dengan melakukan pengawasan pada penyelenggara pelayanan publik, menerima aduan dan menindak lanjuti aduan dari masyarakat dalam tujuannya utuk kepentingan dan kepuasan dari masyarakat.

Inovasi dalam pelayanan publik Oleh Ombudsman RI Bengkulu pun merujuk pada pemanfaatan sosial media sebagai hal yang baru dalam pelayanan publik sebagai alternatif dari pelayanan publik yang biasanya dilakukan secara tradisional. Inovasi itu sendiri pada dasarnya dipahami sebagai suatu gagasan, tindakan, maupun barang yang dianggap baru oleh individu, dimana konsep kebaruan dalam inovasi tersebut dipandang dan diukur secara subjektif tergantung pada individu yang menangkapnya (Rusmiarti, 2015:88). Menjadi menarik untuk diteliti tentang "konsep" baru yang diterapkan dalam proses pelayanan publik, terlebih salah satu tantangan yang dihadapi oleh lembaga tersebut adalah kurangnya pemahaman masyarakat akan keberadaan lembaga tersebut, sehingga inovasi pada dasarnya diperlukan dalam menjangkau masyarakat dan menjalankan peran sebagai lembaga negara yang totalitas dalam melakukan pelayanan publik sebagai tujuan dari keberadaan lembaga negara tersebut.

Penelitian ini dilakukan untuk melihat sejauh mana sosial media dimanfaatkan oleh Ombudsman RI Bengkulu dalam melakukan pelayanan publik sebagai wujud inovasi dalam pelayanan publik oleh Ombudsman RI Bengkulu, dimana penelitian ini dianalisis dengan menggunakan teori difusi inovasi.

\section{METODE PENELITIAN}

Metode penelitian ini dilakukan dengan menggunakan pendekatan deskriptif kualitatif dimana hasil penelitian dianalisis dengan menggunakan teori difusi inovasi. Subjek penelitian dalam hal ini adalah pihak Ombudsman RI Bengkulu, dan masyarakat pengguna sosial media yang pernah mengakses laman sosial media milik Ombudsman RI Bengkulu yang dibuktikan dengan jejak digital yang ditinggalkan baik dalam bentuk like maupun komentar dalam laman sosial media milik Ombudsman RI Bengkulu. Dalam menentukan informan dan responden penelitian, peneliti menggunakan teknik snowball sampling dan purposive sampling. Teknik snowball sampling digunakan dalam menentukan informan yang berasal dari Ombudsman RI Bengkulu sedangkan purposive sampling digunakan dalam menentukan responden masyarakat, dengan menentukan kriteria yang digunakan dalam menjaring responden yang sesuai dengan tujuan dan hasil yang dibutuhkan dalam penelitian terkait pemanfaatan sosial media dalam pelayanan publik oleh Ombudsman RI Bengkulu, dimana kriteria-kriteria yang ditetapkan diantaranya yakni (1) pengguna sosial media aktif dan memiliki akun sosial media yang jelas. (2) Pernah mengakses (minimal salah satu) laman sosial media Ombudsman RI Bengkulu yang dibuktikan dari jejak digital yang ditinggalkan pada laman sosial media milik Ombudsman RI Bengkulu (baik dalam bentuk komentar maupun "like" pada postingan di laman sosial media Ombudsman RI Bengkulu, dan (3) Bersedia pada saat diminta untuk menjadi responden dalam penelitian (akses ke responden masyarakat dilakukan melalui sosial media).

\section{III.PEMBAHASAN}

Hasil penelitian terkait pemanfaatan sosial media sebagai wujud inovasi dalam pelayanan publik oleh ombudsman RI Bengkulu menunjukkan bahwa dalam prosesnya, Ombudsman RI Bengkulu memanfaatkan beberapa sosial media dalam pelayanan publik, beberapa sosial media tersebut diantaranya facebook, instagram, youtube, dan twitter. Dari ke-empat laman sosial media yang dimanfaatkan oleh Ombudsman RI Bengkulu, facebook adalah laman sosial media yang paling sering digunakan, dan laman sosial media instagram setelahnya. Facebook Ombudsman RI Bengkulu dibentuk sejak tahun 2014 diikuti oleh kurang lebih 4.986 pengguna facebook, dengan rentang waktu postingan minimal 1 kali dalam seminggu (https://web.facebook.com/ ombudsmanri.bengkulu). Sedangkan sosial media Instagram milik Ombudsman RI Bengkulu aktif dalam memberikan postingan sejak 8 Juni 2017, Sampai dengan Juni 2019, jumlah pengikut Instagram milik Ombudsman RI Bengkulu berjumlah kurang lebih 939 pengikut. Jumlah postingan dari akun instagram Ombudsman RI Bengkulu sampai dengan Juni 2019 adalah sebanyak 106 postingan (www.instagram.com/ ombudsmanribengkulu). Dari hasil pengamatan terhadap akun sosial media instagram milik Ombudsman RI Bengkulu tersebut dapat disimpulkan pula bahwa rentang waktu postingan sosial media Instagram milik Ombudsman RI Bengkulu adalah kurang lebih 1 kali dalam seminggu.

Selain Facebook dan Instagram Ombudsman RI Bengkulu pun memanfaatkan Sosial media youtube dan twitter meski pemanfaatannya tidak sebanyak facebook dan instagram yang lebih banyak diakses oleh masyarakat dalam mencari informasi dan menyampaikan aduan kepada pihak Ombudsman RI Bengkulu.

Pemanfaatan sosial media ini merupakan wujud dari difusi inofasi dilihat dari empat elemen dalam proses difusi inovasi menurut M.Rogers yakni Inovasi, Saluran Komunikasi, Jangka Waktu, dan Sistem Sosial. Dengan melihat empat elemen dalam proses difusi inovasi tersebut kita dapat melihat tentang inovasi yang diterapkan dalam proses pelayanan publik oleh Ombudsman RI Bengkulu dan seberapa jauh pemanfaatan inovasi tersebut dalam proses pelayanan publik oleh Ombudsman RI Bengkulu. Dalam hal inovasi, sebagaimana yang dikemukakan oleh Rogers (1983:11) bahwa konsep "kebaruan" dalam inovasi dapat berupa pengetahuan, persuasi, atau keputusan untuk mengadopsi. Pengetahuan dalam hal ini terkait tentang ide atau cara baru yang diterapkan dalam proses pelayanan publik oleh Ombudsman RI Bengkulu dimana sosial media digunakan sebagai medium dalam penyampaian informasi (sosialisasi) oleh Ombudsman RI Bengkulu serta wadah yang dimanfaatkan oleh Ombudsman RI Bengkulu dalam menampung aspirasi maupun aduan dari masyarakat terkait proses pelayanan publik yang diselenggarakan oleh pemerintah maupun lembaga (penghimpun aduan). Dengan adanya pemanfaatan sosial media oleh Ombudsman RI Bengkulu tersebut, masyarakat mulai beralih dari proses penyampaian aduan yang tradisional, menjadi lebih 
Website : http://sosial.unmermadiun.ac.id/index.php/sosial

modern bahkan dirasa lebih mudah, efektif dan efisien, yang mana hal ini merupakan bentuk keputusan masyarakat untuk mengadopsi "cara" baru dalam pelayanan publik yang dilakukan oleh Ombudsman RI Bengkulu.

Saluran Komunikasi merujuk pada sarana dalam penyampaian pesan atas ide-ide baru dalam proses difusi inovasi, ide baru dalam proses pelayanan publik bermedia disalurkan melalui sosial media dimana sosial media selain menjadi wujud dari inovasi itu sendiri pun juga menjadi sarana dalam menyalurkan pesan-pesan yang mengandung "kebaruan" atau inovasi di dalamnya. Seperti halnya penyampaian informasi oleh Ombudmsan RI Bengkulu melalui sosial media diwujudkan dalam foto maupun video yang di posting pada laman sosial media milik Ombudsman RI Bengkulu. Selain penyampaian informasi yang disampaikan dalam wujud yang inovatif, pun penyampaian pesan oleh Ombudsman RI Bengkulu tersebut dirasa lebih efisien karena tidak membutuhkan biaya yang tinggi sebagaimana penyampaian informasi melalui media Konvensional.

Berkenaan tentang waktu dalam proses difusi inovasi menyangkut tentang seberapa banyak masyarakat yang memanfaatkan sosial media sebagai alternatif media dalam mengakses informasi dari Ombudsman RI Bengkulu serta menyampaikan aduan kepada Ombudsman RI Bengkulu mulai dari sosial media dimanfaatkan oleh Ombudsman RI Bengkulu sampai dengan penelitian dilaksanakan. Dari hasil pengamatan selama proses penelitian, akun Facebook Ombudsman RI Bengkulu yang dibentuk sejak tahun 2014 diikuti oleh kurang lebih 4.986 pengguna dan aktif dalam memberikan postingan minimal 1 kali dalam seminggu. Sedangkan instagram Ombudsman RI sejak 2017 sampai dengan Juni 2019, memiliki 939 pengikut dengan jumlah postingan sebanyak 106 postingan. Sejak dimanfaatkannya sosial media sebagai media pelayanan publik, respon pada setiap postingan pada sosial media milik Ombudsman RI Bengkulu dapat dikatakan terus mengalami peningkatan. Begitu pula pada akun sosial media Ombudsman RI Bengkulu lainnya yang meskipun tidak terlalu aktif dalam menyampaikan informasi namun mengalami peningkatan respon pada setiap postingan yang diberikan.

Elemen terakhir dalam proses difusi inovasi adalah sistem sosial dimana sistem sosial berkenaan dengan dampak yang dihasilkan dalam sistem sosial dari proses difusi inovasi yang dilakukan sebagai bentuk konsekuensi dari inovasi yang dilakukan. Dari pemanfaatan sosial media sebagai media pelayanan publik oleh Ombudsman RI Bengkulu, selain dampak positif ada pula dampak negatif sebagai konsekuensi dari kemudahan masyarakat dalam mengakses informasi dan menyampaikan aduannya, yakni kebebasan yang dapat menimbulkan munculnya informasi palsu karena siapapun dapat mengakses laman sosial media Ombudsman RI Bengkulu dan menyampaikan aduannya. Sehingga filter dalam menerima aduan tetap dilakukan oleh Ombudsman RI Bengkulu untuk menghindari munculnya Hoax atau informasi palsu.

\section{IV.KESIMPULAN}

Empat elemen dalam proses difusi inovasi menunjukkan inovasi yang diterapkan dalam proses pelayanan publik oleh Ombudsman RI Bengkulu dan bagaimana pemanfaatan inovasi tersebut dalam proses pelayanan publik oleh Ombudsman RI Bengkulu. Inovasi dalam hal ini berkenaan dengan pemanfaatan sosial media sebagai media sosialisasi dan penghimpun aduan dalam proses pelayanan publik oleh Ombudsman RI Bengkulu. Dikatakan sebagai wujud inovasi karena proses pelayanan publik yang biasa dilakukan secara tradisional baik secara langsung maupun melalui media tradisional sehingga memakan biaya yang cukup tinggi, dengan adanya pemanfaatan sosial media dapat dilakukan secara lebih mudah mudah, cepat dan efisien.

\section{DAFTAR PUSTAKA}

Rogers, Everett M. Diffussions of innovations (Third Edition).London: The Free Press.

Rusmiarti, Dewi Ariningrum. Analisis Difusi Inovasi dan Pengembangan Budaya Kerja pada Organisasi Birokrasi. Jurnal Masyarakat Telematika dan Informasi Vol 6. No.2 November 2015. Hal 85-100

Taprial, Varinder., Kanwar, Priya. 2012. Understanding Social Media. United Kingdom: London Bussiness School

UU No.37/2008 pasal 1 tentang Ombudsman RI

wearesocial.com/global-digital-report-2019

https://web.facebook.com/ ombudsmanri.bengkulu

www.instagram.com/ ombudsmanribengkulu 